\title{
INTERCULTURALIDADE NO ENSINO DE ITALIANO: UM RELATO SOBRE A FORMAÇÃ̃O DE Professores no MUNicípio de São PaUlo
}

\author{
Interculturalità nell'insegnamento dell'italiano: un \\ resoconto sulla formazione di insegnanti nel comune \\ di San Paolo
}

Interculturality in Italian Teaching: A report on
Teacher Education in the City of São Paulo

\author{
Graziele Altino Frangiotti* \\ Ana Luísa de Araújo Mhereb* *
}

RESUMO: Apesar da clara e estreita relação com a língua, a cultura ganhou um papel de destaque no âmbito do ensino-aprendizagem de L2 somente a partir da década de 1990. Ainda assim, até os dias de hoje a inclusão do componente cultural na sala de aula é um grande desafio para os professores de L2 (KUMARAVADIVELU, 2008). Foi justamente com base na importância desse desafio que o tratamento da cultura nas aulas de L2 constituiu um dos temas abordados durante o Suporte Didático para o Ensino da Língua Italiana, inserido no Programa de Formação Multicultural em Língua Italiana para Professores da Rede Municipal de Ensino da Cidade de São Paulo, promovido pelo Instituto Cultural Ítalo-Brasileiro em parceria com a Prefeitura de São Paulo e com o Programa de Pós-Graduação em Língua, Literatura e Cultura Italianas da USP, no segundo semestre de 2020. Propomos apresentar aqui um relato de experiência com o intuito de mostrar como docentes da rede municipal de São Paulo optaram por adotar uma abordagem intercultural na elaboração de projetos para o ensino da língua italiana na escola em que atuam. Em um primeiro momento, mostraremos como a abordagem intercultural foi tratada pelas docentes formadoras nos encontros do referido suporte. Em seguida, descreveremos as propostas de projetos que incorporaram o componente intercultural entre seus objetivos e refletiremos sobre os caminhos encontrados por esses docentes para a inserção de aspectos culturais em suas práticas, apoiando-nos nos conceitos de perspectiva êmica e ética, propostos por Goodenough (1970) e Agar (2007).

*Doutora em Língua, Literatura e Cultura Italianas - Universidade de São Paulo

grazielefrangiotti@gmail.com (ORCID: 0000-0001-6087-7005)

**Doutoranda em Língua, Literatura e Cultura Italianas - Universidade de São Paulo

mhereb.ana@gmail.com (ORCID: 0000-0003-3820-9515)

DOI: http://dx.doi.org/10.11606/issn.2238-8281.v0i42p44-63

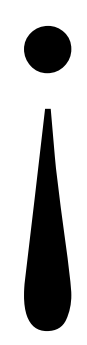


Por fim, elucidaremos como as propostas procuram estimular o desenvolvimento da competência intercultural (BYRAM, 1987; CORBETT, 2003).

PALAVRAS-CHAVE: Interculturalidade; Formação de professores; Ensino de italiano L2; Ensino na cidade de São Paulo.

ABSTRACT: Nonostante il chiaro e stretto rapporto con la lingua, la cultura ha acquisito un ruolo di primo piano nell'insegnamento e nell'apprendimento della L2 solo a partire dagli anni 1990. Tuttavia, l'inclusione della componente culturale in classe è a tutt'oggi una grande sfida per gli insegnanti L2 (KUMARAVADIVELU, 2008). Proprio per l'importanza di questa sfida, la trattazione della cultura nelle classi di italiano L2 è stato uno dei temi affrontati durante il Supporto alla didattica per l'insegnamento della lingua italiana, inserito nel Programma di Formazione Multiculturale in Lingua Italiana per Insegnanti del Comune di San Paolo, promosso dall'Istituto Culturale Italo-Brasiliano in collaborazione con il Comune di San Paolo e con la Scuola di Master e Dottorato in Lingua, Letteratura e Cultura Italiana dell'Università di San Paolo, svoltosi durante la seconda metà del 2020. Proponiamo di presentare qui un resoconto dell'esperienza per mostrare come gli insegnanti coinvolti nelle attività di supporto hanno scelto di adottare un approccio interculturale nell'elaborazione di progetti per l'insegnamento della lingua italiana nella scuola in cui operano. In un primo momento, mostreremo in che modo l'approccio interculturale è stato trattato dagli insegnanti formatori negli incontri del suddetto lavoro di supporto. Successivamente, descriveremo le proposte dei progetti che hanno incorporato la componente interculturale tra i loro obiettivi e rifletteremo sui percorsi individuati da questi docenti per l'inserimento degli aspetti culturali nelle loro pratiche, basandoci sui concetti di prospettiva emica ed etica, proposti da Goodenough (1970) e Agar (2007). Infine, delineeremo come le proposte cercano di stimolare lo sviluppo della competenza interculturale (BYRAM, 1987; CORBETT, 2003).

PAROLE CHIAVE: Interculturalità; Formazione di insegnanti; Insegnamento di italiano L2; Insegnamento nel comune di San Paolo.

ABSTRACT: Culture has played a prominent role in the scope of L2 teaching and learning only since the 1990s, despite its clear relationship with language. Even so, nowadays the inclusion of the cultural component in the classroom is still a great challenge for L2 teachers (KUMARAVADIVELU, 2008). Based on the importance of such challenge, the treatment of culture in L2 classes was one of the topics covered during the Didactic Support for Italian Teaching, included in the Multicultural Training Program in Italian Language for Teachers of the Municipal Education System of the City of São Paulo, promoted by the Instituto Cultural Ítalo-Brasileiro in partnership with the city of São Paulo and with the Graduate Program in Italian Language, Literature and Culture of the Universidade de São Paulo, in the second half of 2020. We propose an 
experience report in order to show how teachers of the municipal schools of São Paulo have chosen to take an intercultural approach in the development of projects for teaching Italian in the schools where they work. At first, we will show how the intercultural approach was treated by the teacher educators in the meetings of the aforementioned support. Then, we will describe the project proposals that incorporated the intercultural component among their goals and will reflect on the paths found by these teachers for the insertion of cultural aspects in their practices, based on the concepts of emics and ethics, as proposed by Goodenough (1970) and Agar (2007). Finally, we will elucidate how the proposals seek to stimulate the development of intercultural competence (BYRAM, 1987; CORBETT, 2003).

KEYWORDS: Interculturality; Teacher education; Italian L2; Teaching in the city of São Paulo. 


\section{Introdução}

Há décadas, a ideia de cultura tem sido considerada indispensável para o ensino-aprendizagem de uma língua estrangeira ou segunda língua (L2 ${ }^{1}$ daqui em diante). Uma das concepções de cultura, segundo Spencer-Oatey (2012), refere-se ao sistema de regras e valores compartilhados pelos integrantes de uma determinada sociedade. Representa, assim, um sistema de orientação que influencia as percepções e as atitudes dos indivíduos. Não à toa Vygotsky afirma que é justamente a cultura, definida pelo autor como "um produto, ao mesmo tempo, da vida social e da atividade social do homem" (1997, p. 106), que diferencia os seres humanos dos animais.

Indo ao encontro desses posicionamentos, o filósofo Bauman (1999) afirma que a cultura está longe de ser um conceito unívoco. De fato, por sua complexidade, seria impossível defini-la de uma única maneira, pois, como em um prisma, por cada ângulo que a olharmos teremos um aspecto sobressalente. Diante dessa dificuldade epistemológica, o filósofo explana três maneiras de enxergá-la: em primeiro lugar, de um ponto de vista hierárquico, posteriormente, diferencial e, enfim, genérico.

A perspectiva hierárquica do conceito de cultura diz respeito ao senso comum do termo, correspondendo à ideia de que existiriam pessoas, países e sociedades com mais cultura que outros. Partindo dessa lógica, se a uma pessoa é atribuído um alto grau de cultura, isso quer dizer que ela é tida como bem educada, cortês, urbana e nobre. Por outro lado, se um indivíduo é considerado "sem cultura", então se assume tacitamente que ele não possui nenhum desses atributos.

Na segunda acepção, o termo "cultura" é empregado para explicar as diferenças aparentes entre comunidades de pessoas, podendo ser essas discrepâncias frutos do tempo, do ambiente ou de elementos na sociedade. Segundo sustenta Bauman, essa concepção, embora ligada a épocas mais recentes, não era desconhecida do mundo clássico, tanto que os gregos em seus registros já se referiam aos povos que encontravam através da fórmula "eles não fazem $\mathrm{x}$, ao contrário de nós, que fazemos x".

Essa visão de cultura coincide com aquela sugerida por Spencer-Oatey (2012), uma vez que elimina o juízo de valor presente na ótica hierárquica, colocando no mesmo patamar as diferentes culturas, ao invés de estabelecer níveis entre elas, ao mesmo tempo em que exclui a possibilidade de pessoas ou comunidades não a possuírem. Desse modo, não se trataria de ter ou não cultura, mas sim de reconhecer as semelhanças e diferenças culturais entre as sociedades. Além disso, não haveria uma cultura única a ser adquirida, mas sim culturas, no plural, formadas no e pelo compartilhamento de experiências entre os grupos humanos.

Finalmente, a perspectiva genérica coincide com a definição dada por Vygotsky, segundo a qual a cultura constitui aquilo que diferencia o mundo dos seres humanos, de um lado, e o mundo das criaturas vivas não humanas, de outro.

Para Kramsch (1998), a língua é o principal meio pelo qual a vida social é conduzida. Por meio dela, segundo a autora, a realidade social é refletida e moldada. Nesse sentido, a língua

1 Embora, muitas vezes, na literatura seja feita a distinção entre língua estrangeira (LE) e segunda língua (L2) de acordo com o contexto de aprendizagem, neste trabalho utilizaremos L2 como referência a ambos. 
consiste em um modo de expressão cultural de ideias compartilhadas por determinados grupos sociais. A relação entre língua e cultura é tão profunda que Agar (2002) propõe o conceito de languaculture, o qual veicula as duas noções, na medida em que insere a cultura no interior da linguagem, ao mesmo tempo em que assume que a linguagem está carregada de cultura.

Para Agar, "a cultura começa quando você percebe que teve um problema com a linguagem e o problema tem a ver com quem você é"’ (2002, p. 21-22). Em outras palavras, a cultura estaria relacionada com a percepção de que o seu modo de ser e estar no mundo difere do modo de ser e estar no mundo do seu interlocutor. Logo, ela envolveria a tomada de consciência de que o que é natural ou correto para alguém não constitui algo absoluto, mas simplesmente uma dentre as inúmeras alternativas de ver o mundo. Com base nessas ideias, Agar sustenta que aprender uma nova língua significa se abrir para o novo, ou seja, ampliar a própria consciência sobre o funcionamento do mundo, indo além daquilo que ele denomina conhecimento da gramática e do dicionário.

Apesar da clara a estreita relação entre língua e cultura, somente com a expansão da comunicação internacional e do comércio no contexto pós Segunda Guerra Mundial, foi reconhecida a necessidade de se ensinar aspectos culturais nas aulas de L2 (KUMARAVADIVELU, 2008). A partir dos anos de 1990, quando se intensificaram as migrações e o interesse pelo multiculturalismo, a cultura ganhou um papel de destaque no âmbito do ensino-aprendizagem de L2. No entanto, segundo Kumaravadivelu (2008), a inclusão do componente cultural na sala de aula é um grande desafio para os professores de L2 até os dias de hoje.

Foi justamente com base na importância desse desafio que a inserção da cultura nas aulas de L2 constituiu um dos temas tratados durante o chamado "Suporte Didático para o Ensino da Língua Italiana", inserido no Programa de Formação Multicultural em Língua Italiana para Professores da Rede Municipal de Ensino da Cidade de São Paulo. O Programa, promovido pelo Instituto Cultural Ítalo-Brasileiro (ICIB) ${ }^{3}$ e pela Prefeitura de São Paulo, em parceria com o Programa de Pós-Graduação em Língua, Literatura e Cultura Italianas da Universidade de São Paulo, tem o objetivo de capacitar os docentes da rede municipal para incluir o ensino da língua e da cultura italiana nas escolas municipais de São Paulo.

Neste relato de experiência, mostraremos, em um primeiro momento, como a abordagem intercultural foi tratada pelas docentes formadoras nos encontros do referido suporte. Posteriormente, descreveremos as propostas de projetos que foram apresentadas no último encontro pelos professores que frequentaram o suporte, dando ênfase especial àqueles que incorporaram a componente intercultural entre seus objetivos. Em seguida, refletiremos sobre os caminhos encontrados pelos docentes, que atuam em diferentes disciplinas, para a inserção de aspectos culturais em suas práticas.

$2 \quad$ No original: “Culture starts when you realize that you've got a problem with language, and the problem has to do with who you are". Exceto onde explicitado, as traduções deste artigo são de nossa autoria.

3 O Instituto Cultural Ítalo-Brasileiro (ICIB) é ente promotore do Ministero degli Affari Esteri e della Cooperazione Internazionale (MAECI) e essa iniciativa com os professores das escolas municipais de São Paulo é parte do projeto aprovado. 


\section{A interculturalidade em foco}

A ideia de interculturalidade nasce do encontro entre diferentes línguas e culturas. No âmbito do ensino de L2, a abordagem intercultural originou-se a partir da abordagem comunicativa e ganhou destaque a partir do final da década de 1980.

Um defensor dessa perspectiva de ensino é Corbett (2003). Ele define assim a competência comunicativa intercultural:

A competência comunicativa intercultural inclui a habilidade de compreender a língua e o comportamento da comunidade-alvo e explicá-los aos membros da comunidade de partida - e vice-versa. Em outras palavras, uma abordagem intercultural treina os aprendizes para serem "diplomatas", capazes de ver diferentes culturas a partir de uma perspectiva de compreensão consciente. Esse objetivo efetivamente substitui o objetivo de longa data, embora raramente alcançado, de ensinar os aprendizes a atingir a "proficiência do falante nativo". Obviamente, um dos principais objetivos de uma abordagem intercultural continua sendo o desenvolvimento e o aprimoramento da linguagem; no entanto, esse objetivo está ligado ao objetivo igualmente importante de compreensão e mediação intercultural. (CORBETT, 2003, p. 2) ${ }^{4}$

Dessa forma, coloca-se como meta da aprendizagem de línguas não mais o desenvolvimento da proficiência similar à do falante nativo, algo que, como o próprio autor enfatiza, é raramente atingido, mas sim uma compreensão da língua/cultura-alvo que vai além do senso comum, do estereótipo, formando um aprendiz "diplomata", isto é, capaz de perceber as diferenças entre culturas, compreendê-las, respeitá-las e mediá-las.

Como recorda Corbett, Byram (1997) produziu um elenco, enumerando atitudes que podem favorecer a ampliação da competência comunicativa intercultural. Entre outros pontos, a lista contempla os seguintes tópicos:

(1) Conhecimento de si mesmo e do outro; de como ocorre a interação; da relação do indivíduo com a sociedade;

(2) Saber interpretar e relacionar informações;

(3) Saber descobrir informações culturais;

(4) Saber relativizar a si mesmo e valorizar as atitudes e crenças do outro.

Assim, desenvolver a competência comunicativa intercultural abrange tanto uma tomada de consciência de si mesmo quanto o reconhecimento da alteridade. Graças a esse processo, que inclui o saber descobrir, interpretar, relacionar e relativizar informações sobre a cultura-alvo, o

$4 \quad$ No original: "Intercultural communicative competence includes the ability to understand the language and behaviour of the target community, and explain it to members of the 'home' community - and vice versa. In other words, an intercultural approach trains learners to be 'diplomats', able to view different cultures from a perspective of informed understanding. This aim effectively displaces the long-standing, if seldom achieved, objective of teaching learners to attain 'native speaker proficiency'. Obviously, one key goal of an intercultural approach remains language development and improvement; however, this goal is wedded to the equally important aim of intercultural understanding and mediation" (CORBETT, 2003, p. 2). 
estudante poderá se tornar cada vez mais curioso em relação a novas sociedades, novas crenças, novas maneiras de viver, transformando-se em um cidadão aberto e consciente do valor de sua própria cultura e da cultura do outro.

Nessa mesma linha de raciocínio, segundo Serra Borneto, a aprendizagem intercultural é um processo "nel quale la lingua straniera viene riconosciuta e considerata come espressione di un pensiero e di un modo di vivere diverso" (1998, p. 211). Por meio da interculturalidade em sala de aula seria então possível compreender melhor a cultura do outro e, ao mesmo tempo, a própria. Com essa abordagem, o aprendiz de uma L2 passaria a ter o papel de mediador de duas culturas: a da sua L1 e a da L2.

Com o progressivo reconhecimento da importância do conceito de competência intercultural, muitos profissionais da área do ensino têm buscado maneiras de incorporar aspectos culturais às aulas de L2. Para projetar caminhos que conduzam nessa direção, nos parecem particularmente interessantes os conceitos de perspectiva êmica e ética, como compreendidos por Agar (2010).

O autor recorre à definição inicialmente concebida pelo linguista Kenneth Pike (1967) e posteriormente retrabalhada pelo antropólogo Ward Goodenough (1970), segundo a qual a bipartição êmico/ético teria suas origens na Fonologia tradicional, que separa o estudo dos sons universais - a Fonética - do estudo dos sons em uma dada língua - a Fonêmica. Nas palavras de Agar:

A fonética é uma ortografia para os possíveis sons que um ser humano pode produzir com seu equipamento articulatório. A fonêmica, por sua vez, usa essa notação para descobrir o subconjunto daqueles sons possíveis que marcam uma distinção para os falantes de uma determinada língua (...). A fonética é universal; a fonêmica é específica de uma língua em um determinado grupo em um determinado momento. (AGAR, 2010, p. 38)

Segundo essa diferenciação, então, a Fonética teria como meta recobrir a descrição de todos os sons possíveis que um ser humano dotado de um sistema articulatório pode realizar. Já a Fonêmica constituiria a aplicação das categorias presentes na Fonética para o estudo de realidades linguísticas historicamente situadas.

Transpondo esse entendimento dos sufixos êmico e ético aos estudos culturais, Goodenough (1970) observa a ilha de Truk e concentra-se em verificar como os habitantes da região compreendem a noção de propriedade. Com os resultados que obteve e comparando-os com sua própria matriz cultural angloamericana, Goodenough conclui que esse é um exemplo de como um aspecto ético universal - a propriedade - pode se desenvolver em diferentes realidades êmicas. Ele ainda acrescenta:

$5 \quad$ No original: "Phonetic is an ortography for most of possible sounds that a human can produce given their articulatory equipment. Phonemics, in turn, uses that notation to figure out the subset of those possible sounds that signal a difference to speakers of a particular language [...] Phonetic is universal; phonemics is specific to a language among some group at some point in time" (AGAR, 2010, p. 38). 
uma vez que essas distinções na ilha de Truk foram aprendidas por um etnógrafo - ou por qualquer outra pessoa - elas poderiam ser adicionadas ao 'kit ético de possibilidades' em um domínio humano universal. (GOODENOUGH, 1970, p. 42)

Em outras palavras, o estudo a partir de categorias universais (como a da propriedade) possibilita a descrição de realidades locais (como a da ilha de Truk), a qual, por sua vez, enriquece o "kit ético de possibilidades humanas", em um processo contínuo de retroalimentação entre as dimensões ética (universal) e êmica (local).

Embora saibamos que essa diferenciação entre êmico/ético tenha sido formulada, sobretudo, para dar bases a teorias antropológicas e etnográficas, acreditamos que sua transposição para o ensino de línguas seja possível, pois, como sustenta Agar, "ética e êmica são, ambas, partes de qualquer compreensão humana" ${ }^{\text {" }}$ (2007, p. 1374).

Dessa maneira, tomando emprestado o conjunto de reflexões de Goodenough e aproximando-o do ensino de L2, parece possível pensar que a apresentação em sala de aula de aspectos culturais da comunidade em que a língua-alvo é falada se enquadra mais diretamente em uma perspectiva êmica, já que focaliza uma realidade local em um momento histórico específico.

No entanto, ao se promoverem discussões com enfoque cross-cultural, nas quais a matriz cultural do aluno é comparada com a da comunidade-alvo (ou ainda com a de diferentes comunidades), haverá a ampliação do "kit de possibilidades", fazendo com que esse aluno se dê conta de que muitas formas de viver e de se relacionar são possíveis e de que a maneira como ele vive e se relaciona constitui apenas um dos diferentes caminhos.

A partir dessa ótica, o ensino de L2 entendido aqui tem o objetivo de promover o entrecruzamento e o reconhecimento das múltiplas realidades culturais, ampliando a visão do todo por parte do aluno. Ao mesmo tempo, poderá despertar nele a compreensão de que é justamente esse núcleo de fatores compartilhados universalmente que nos une e diferencia enquanto seres humanos.

Tendo finalizado as considerações sobre os conceitos de interculturalidade e de perspectiva êmica e ética, no próximo parágrafo nos deteremos sobre a metodologia da experiência didática.

\section{Metodologia}

\subsection{O contexto da pesquisa: o suporte didático}

Como foi exposto na introdução deste artigo, participaram da experiência de suporte didático sete docentes formadoras, todas mestras, doutorandas ou doutoras em língua italiana pelo Programa de Pós-Graduação em Língua, Literatura e Cultura Italianas da Universidade de São

$6 \quad$ No original: "once those Trukese distinctions were learned by an ethnographer - or by anyone else for that matter - they could be added to the 'etic kit of possibilities' in a universal human domain." (GOODENOUGH, 1970, p. 42)

$7 \quad$ No original: "Etic and emic are both part of any human understanding" (AGAR, 2007, p. 1374) 
Paulo. Do ponto de vista prático, essa atuação em conjunto se traduziu em um percurso pensado coletivamente, cuja elaboração se deu em reuniões semanais a distância, durante as quais as formadoras não apenas definiam os temas e textos a serem abordados, como também avaliavam o progresso das atividades desenvolvidas durante os encontros.

É importante ressaltar que, embora os temas e textos fossem escolhidos pelo grupo, cada formadora era livre para formular e conduzir suas próprias aulas de acordo com o perfil e as necessidades dos alunos. Portanto, não se tinha como objetivo encontros padronizados, o que significa que os textos escolhidos eram os mesmos, mas que o suporte tomava rumos diversos em decorrência do trabalho individual das professoras formadoras e da atuação dos discentes.

No caso do relato ora proposto, trata-se da experiência de duas das formadoras, não sendo possível, portanto, estender os resultados que serão aqui descritos aos demais grupos participantes do suporte.

Feita essa ressalva inicial, cabe dizer que a experiência foi estruturada a partir da seleção de temas relativos à didática de L2, os quais deviam ser discutidos ao longo de 14 encontros (o último encontro foi reservado para a apresentação oral das propostas de projetos formuladas pelos docentes que frequentaram o suporte). De modo geral, o grupo de formadoras optou por seguir uma perspectiva didática que partia de assuntos introdutórios, como o que é ensinar e aprender, para chegar a aspectos mais específicos, como os métodos e as técnicas disponíveis para o ensino de L2. Os assuntos abordados foram:

- o que é ensinar

- metodologia por projetos

- fases de um projeto

- exemplo de aulas baseadas em projeto

- metodologia CLIL

- exemplo de aulas com a metodologia CLIL

- revisão dos métodos de ensino de línguas ao longo do tempo

- didática lúdica

- exemplos de atividades lúdicas

- estrutura de uma unidade didática

- estrutura de um projeto de ensino

Neste relato, nos concentraremos na temática "revisão dos métodos de ensino de línguas ao longo do tempo", apresentada entre a sétima e a oitava aulas. Para o tratamento desse tema, foi proposto o primeiro capítulo da obra C'era una volta Il metodo de Serra Borneto (1998), que apresenta sumariamente algumas das diferentes metodologias de ensino que estiveram no centro da atividade docente ao longo do século XX. Em especial, o autor traz uma breve descrição dos seguintes métodos: gramática-tradução, áudio-oral, humanistas, abordagem comunicativa e abordagem intercultural. 


\subsection{O formato e o conteúdo das aulas ministradas}

Apresentaremos a seguir o formato das aulas das duas autoras do presente artigo. A primeira estruturou a aula da seguinte maneira: em primeiro lugar, foi proposta a leitura de cinco segmentos extraídos do texto. Em seguida, os alunos deviam relacionar as características dos métodos a seus nomes, como exemplificado no quadro (Quadro 1) a seguir:

Quadro 1 - Exemplo de atividade realizada durante o Suporte didático

\section{ISTRUZIONI:}

In questo testo intitolato "C'era una volta il metodo" di Borneto (1998), sarà presentata una retrospettiva di sei metodi d'insegnamento per le lingue straniere. Leggine le differenti parti e poi abbina il metodo al suo nome corretto.

1) Metodo audiorale

2) Approccio comunicativo

3) Metodi umanistici-affettivi

4) L'approccio interculturale

5) Metodo grammatico-traduttivo

\begin{tabular}{|l|l|}
\hline A. 5 & $\begin{array}{l}\text { É uno dei metodi più tradizionali ancora parzialmente in uso. In questo metodo } \\
\text { all'insegnante viene richie-sto di conoscere bene la grammatica della lingua } \\
\text { straniera, di cono-scere il meglio possibile la lingua stessa e di far svolgere } \\
\text { esercizi e traduzioni, correggere composizioni ecc. La lezione è di tipo fron-tale } \\
\text { e l'insegnante può di norma fare leva su un libro ben strutturato, frutto di una } \\
\text { lunga tradizione di studi grammaticali e di tentati-vi pedagogici. Il libro lo si può } \\
\text { seguire in linea di principio passo a passo e prevede spesso una serie di esercizi } \\
\text { graduali. Gli allievi ri-conoscono all'insegnante competenza e autorità e } \\
\text { accettano san-zioni, per esempio quelle connesse alla valutazione degli errori } \\
\text { nei compiti scritti. }\end{array}$ \\
\hline B. 1 & $\begin{array}{l}\text { Questo metodo si è diffuso nel dopoguerra prima negli Stati Uniti e poi anche in } \\
\text { Europa, possiede diversi presupposti come, per esempio, la situatività, l'uso } \\
\text { della lingua orale e l'apprendimento induttivo e implicito. L'introduzione di una } \\
\text { progressione rigorosa nelle strutture, la scarsa elasticità tipica degli esercizi } \\
\text { strutturali, l'uso obbligatorio del laboratorio linguistico, sono tutti aspetti che } \\
\text { impongono all'insegnante una tabella di marcia quasi obbliga-ta. Nel rapporto } \\
\text { con gli studenti l'insegnante è un leader: ne orche-stra gli interventi, li stimola } \\
\text { direttamente, e rappresenta il modello linguistico da imitare in classe. Nel } \\
\text { complesso, il metodo si può definire ancora altamente strutturato. }\end{array}$ \\
\hline
\end{tabular}


Após a leitura e realização da atividade de correlação, foi proposto que os docentes se reunissem em duplas ou trios para discutir e completar um questionário no qual deviam identificar o papel do professor e do aluno, além de refletir sobre a visão de língua e as possíveis diferenças entre os diversos métodos. Depois disso, deviam relatar ao grupo o que discutiram, propondo uma síntese escrita em italiano das conclusões às quais chegaram.

A segunda autora, embora tenha baseado a aula nos mesmos trechos do capítulo de Serra Borneto, conduziu as atividades de forma diferente. Divididos em duplas ou trios, foi proposto que os discentes lessem somente um dos trechos, focando sua atenção nos seguintes aspectos: o papel do docente e do discente no método referido, a maneira como a língua é aprendida e os materiais utilizados. Após a leitura realizada individualmente, duplas e trios se reuniram com o objetivo de elaborar uma única resposta que envolvesse os elementos mencionados anteriormente. Em seguida, com toda a classe reunida, os grupos apresentaram as características de tais métodos ou abordagens. Ao final de cada apresentação, abria-se para a discussão, momento em que poderiam apontar elementos novos, comentar aspectos considerados especialmente relevantes e relacionar o que foi lido com a própria experiência enquanto professor e/ou aprendiz de uma L2.

As aulas foram ministradas para três grupos de docentes, totalizando 23 professores/alunos - 14 com uma das autoras e nove com a outra. Desse total, 17 atuam na rede pública do município de São Paulo como professores da área de humanas (distribuídos entre as disciplinas de língua portuguesa, inglês, espanhol, geografia, história, artes, além de três professores polivalentes que atuam no ensino fundamental 1), e seis na área de ciências biológicas (todos professores de ciências no fundamental 2).

Como etapa final do suporte didático, foi solicitado aos docentes que apresentassem um projeto de ensino que pudesse ser efetivamente aplicado no ano de 2021 a alunos do ensino fundamental 1 e 2 nas escolas municipais de São Paulo em que atuavam. As propostas deviam levar em conta os métodos e técnicas discutidos durante o suporte e, ao mesmo tempo, englobar a língua italiana ou estar de alguma forma vinculado à Itália.

A seguir, relataremos alguns dos projetos formulados, dando especial ênfase àqueles que privilegiaram a perspectiva intercultural.

\section{Resultados}

Os projetos entregues ao fim do suporte didático foram desenvolvidos individualmente. Cada aluno pôde refletir ao longo do semestre sobre a sua própria área de atuação, de modo a selecionar um tema que tivesse relação com a língua italiana ou com a Itália e que pudesse ser trabalhado através de metodologias de ensino de línguas atuais e em compasso com a visão de ensino adotada no município de São Paulo. 
Como já mencionado, ao todo foram entregues 23 projetos. As abordagens didáticas presentes nesses projetos são sintetizadas a seguir (Gráfico 1$)^{8}$ :

Gráfico 1 - Abordagens didáticas identificadas nos projetos

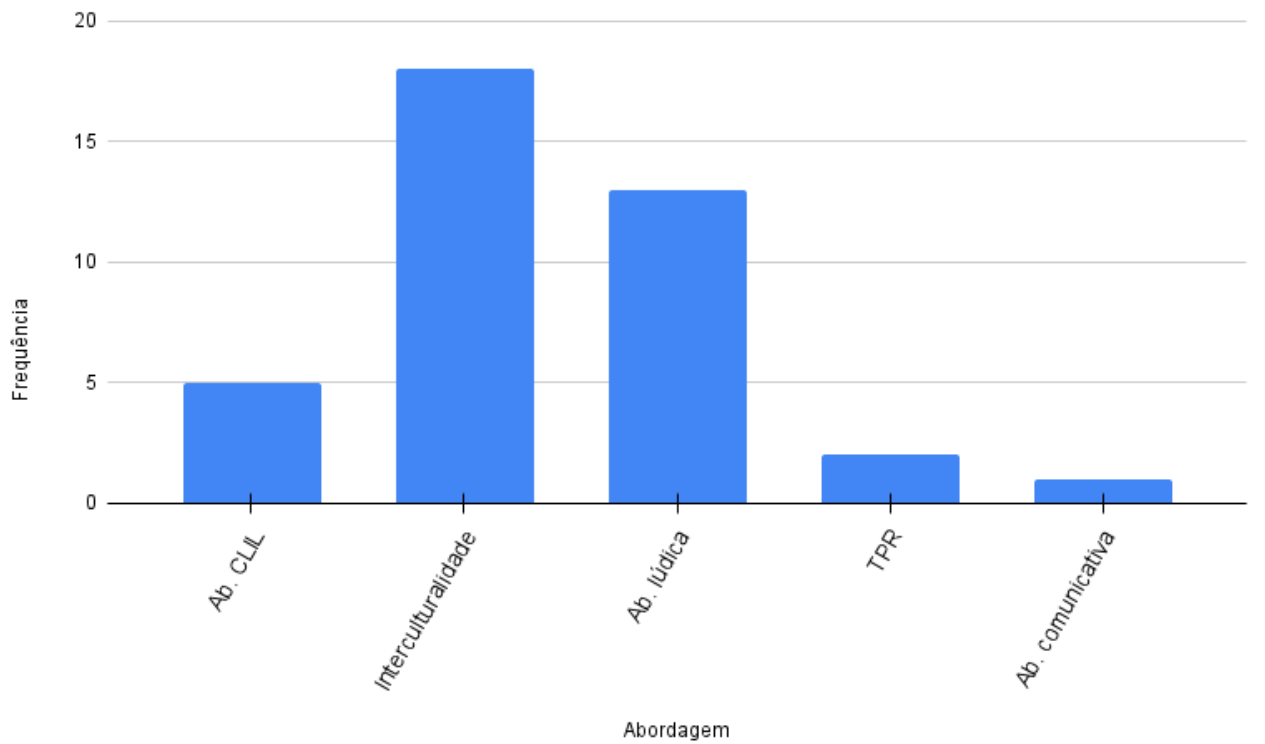

A partir desses dados, é possível notar uma nítida predileção pela abordagem lúdica e pelo ensino intercultural, que foram incorporados, respectivamente, em 13 e 18 projetos. É de se destacar, contudo, que o ensino através da abordagem lúdica, assim como o ensino pelo Content Language Integrated Learning (CLIL), mencionado em cinco projetos, receberam grande atenção no suporte, pois constituíram temas de aulas inteiras. Nessas ocasiões, foram tratadas não apenas as bases dessas metodologias, mas também fornecidos exemplos de aulas e atividades. Já o ensino por meio da perspectiva intercultural não foi alvo de longa explanação, tendo sido contemplado apenas nas atividades realizadas com base no texto de Serra Borneto, como descrito anteriormente.

Esse dado nos faz pensar que o ensino de aspectos culturais, apesar de não ter sido foco central de nenhuma aula, é compreendido pelos professores como uma necessidade inerente

$8 \quad$ Cabe esclarecer que um único projeto poderia englobar mais de um tema, por isso o total de temas (39) não coincide com o número de projetos entregues (23). 
ao ensino de línguas, devendo ser incorporado independentemente da disciplina ofertada pelo professor ou da idade dos alunos.

Aprofundando a nossa análise dos projetos que atrelaram explicitamente o ensino de língua à cultura italiana, pudemos identificar que os temas enfocados pelos docentes foram os seguintes (Gráfico 2):

Gráfico 2 - Temas encontrados nos projetos

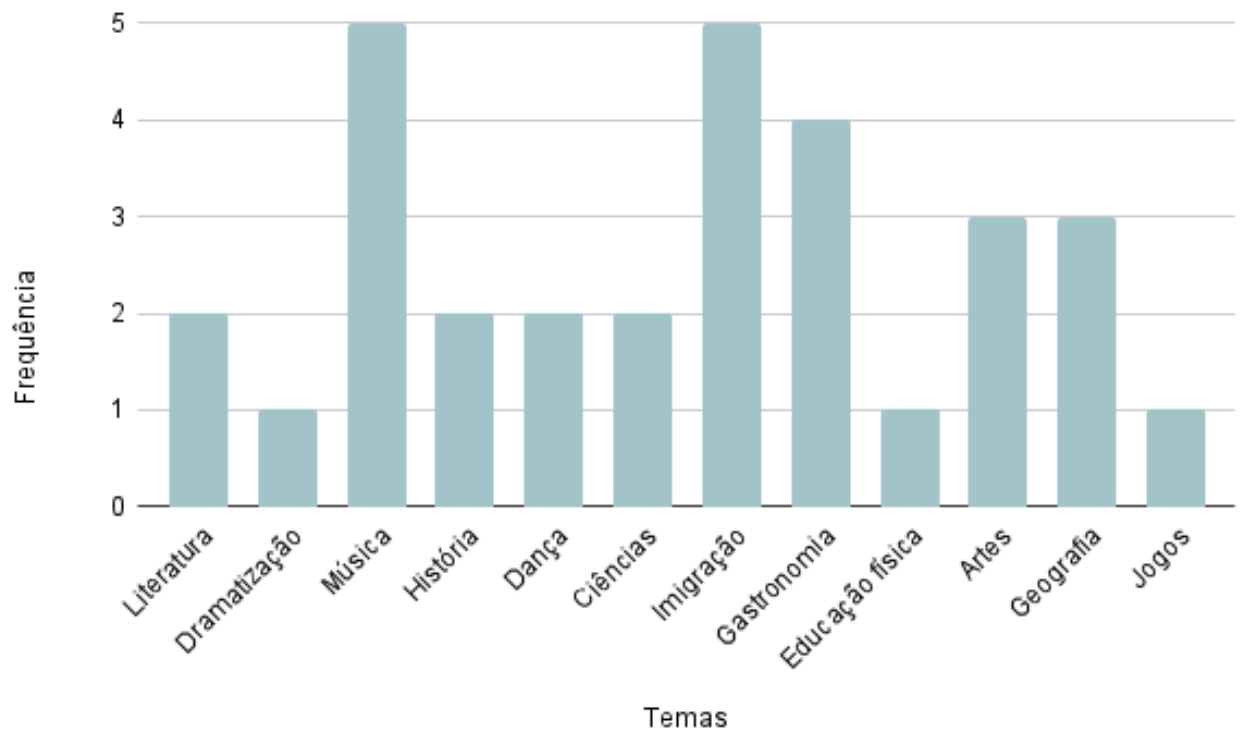

Como é possível observar, os temas mais privilegiados nos projetos foram música, imigração e gastronomia, mostrando que esses parecem ser os tópicos que mais chamam a atenção dos professores quando a intenção é tratar aspectos culturais em sala de aula.

A nosso ver, esses assuntos estavam presentes em vários projetos justamente pelo fato de a Itália ser um país mundialmente conhecido pela forte influência gastronômica e musical. Já no que concerne ao tema da imigração, acreditamos que tenha atingido alta frequência por conta da expressiva presença de italianos e de seus descendentes, especialmente, na cidade e no estado de São Paulo.

De modo geral, os projetos podem ser agrupados em três grandes eixos temáticos: 1) interculturalidade, imigração, história e geografia; 2) interculturalidade e artes; 3 ) interculturalidade e ciências. A seguir, os projetos serão brevemente descritos, para, em seguida, refletirmos sobre como podem contribuir para o desenvolvimento da competência intercultural em sala de aula. 


\subsection{Interculturalidade, imigração, história e geografia}

Do total de projetos apresentados, cinco visam à aplicação de sequências didáticas cujo fio condutor principal é a temática da imigração italiana no Brasil. Nesses projetos, enfatiza-se a história desse período e traça-se um percurso didático que abarca a geografia italiana e, em dois casos, também a gastronomia do país. Essas propostas foram formuladas por quatro professores que atuam no ensino fundamental (de $\mathrm{P} 1$ a $\mathrm{P}^{\circ}$ ) e por um que desenvolve projetos para o ensino de jovens e adultos (P5).

No projeto formulado por P1 (professora polivalente), é feita uma proposta de ensino de italiano com sequências didáticas que têm como finalidade promover o contato com essa língua, possibilitando o desenvolvimento de habilidades de comunicação de nível básico. O primeiro tema a ser abordado é a história da imigração italiana, a partir do conhecimento da origem dos familiares dos alunos. Os temas seguintes envolvem a localização da Itália na Europa, a sua bandeira, as principais datas comemorativas, a história de Roma, a gastronomia, a música do país e, por fim, o "tour final", em que se prevê convidar as famílias dos alunos para um jantar, com a exposição das produções realizadas ao longo do semestre.

As sequências didáticas pensadas por P5 (professora de inglês) justificam-se pela imigração italiana em São Paulo e têm como meta desenvolver o interesse dos estudantes pela língua e cultura italiana por meio da gastronomia. A partir da apresentação de textos culinários sobre a pizza napolitana, a proposta é fazer pesquisas sobre a cultura e a história da cidade de Nápoles, com o objetivo de propiciar o contato dos estudantes com a língua italiana de forma lúdica e prazerosa, encontrando similaridades entre a língua materna e a italiana.

O percurso idealizado por P4 (língua portuguesa) pretende proporcionar um primeiro contato com a língua italiana. Busca-se, além disso, viabilizar um ambiente favorável para a aprendizagem da cultura italiana, partindo da presença de italianos em espaços da cidade de São Paulo, como edifícios, praças e bairros da cidade.

Similarmente, a proposta de P2 (ciências) também envolve o ensino da língua italiana por meio de elementos culturais e a reflexão sobre suas influências na cultura paulistana, voltando-se para o desenvolvimento de uma visão crítica sobre o papel da imigração italiana na formação da sociedade paulistana. Espera-se que os estudantes reconheçam características básicas da língua e da cultura italianas e saibam identificar sua presença na cultura paulistana (como em expressões e ditados populares, na culinária, na história da cidade), de modo que o projeto suscite a vontade de conhecer mais a Itália, assim como outros países que influenciaram a cultura brasileira.

Assim como nos projetos de $\mathrm{P} 4$ e P2, P3 (professora de artes) propõe a reflexão sobre a influência da cultura italiana na identidade nacional e, especificamente, na identidade paulistana. Entre os objetivos estão a sensibilização dos alunos em relação à presença da língua italiana em nosso dia a dia, assim como a reflexão sobre o processo migratório de italianos na cidade de São Paulo.

9 Os nomes dos professores foram substituídos pelas siglas P1, P2, P3 por questões de ética. 
Nesse eixo temático também estão incluídos projetos como os de P6 e P7, que têm como cerne o tratamento de aspectos geográficos da Itália e de como esses fatores influencia(ra)m a organização dessa sociedade.

No caso de P6 (professora polivalente), é previsto o ensino a partir de dois eixos principais: o linguístico, com o desenvolvimento de pequenos diálogos para iniciantes, e o cultural, com a apresentação das características geográficas da Itália por meio de filmes curtos sobre suas principais cidades, além da leitura de mapas e a escuta de músicas e de áudios informativos.

O projeto de P7 (geografia), por outro lado, é ainda mais centrado na disciplina de geografia, pois dá enfoque especial para o aprendizado de conceitos específicos sobre os diferentes tipos de relevo. Nele se propõem o reconhecimento e a diferenciação das principais formas de relevo, a identificação dos agentes internos e externos que levam à sua transformação e a reflexão sobre a importância desse elemento na composição da sociedade italiana, com destaque especial para os efeitos sobre a formação das cidades e as diferentes formas de desenvolvimento econômico.

\subsection{Interculturalidade e artes}

Entre os projetos que partem de uma perspectiva intercultural, há sete cujo tema principal é o ensino de italiano por meio das artes, como música, dança e literatura.

Integrado à disciplina de história, a docente P8 (história) formulou uma sequência didática que tem como finalidade a apresentação da língua italiana por meio da canção Bella ciao e da comparação entre as diferentes versões em língua italiana e a versão brasileira. $\mathrm{O}$ foco aqui recai sobre as condições de trabalho no século passado na Itália, a compreensão do conceito de antifascismo nascido durante a Segunda Guerra Mundial e a reflexão sobre sua utilização como termo global nos dias de hoje.

Ainda com ênfase no trabalho conjunto entre música e história, P9 (espanhol) formulou um projeto com canções italianas que foram traduzidas para o português. Durante as aulas, prevê-se o incentivo à interdisciplinaridade entre língua, música, cultura e história, bem como o desenvolvimento integral dos educandos por meio de atividades musicais e linguísticas que procurem fazê-los vivenciar a prática da música como elemento estético e de expressão artística.

De maneira semelhante, o projeto proposto por P10 (língua portuguesa) envolve a interdisciplinaridade entre língua, música e dança. Com o objetivo de oferecer um panorama histórico e cultural da música italiana, o projeto é constituído por três módulos, com oficinas de língua, de música e de dança. Assim como proposto por P9, o projeto inclui o estudo de canções italianas para as quais há versões brasileiras.

Aliadas à literatura, as propostas de P11 (polivalente) e de P12 (língua portuguesa) têm por objetivo ocasionar o primeiro contato de crianças recém-alfabetizadas com a língua italiana partindo de obras literárias. No caso de P11, prevê-se que o contato aconteça por meio de contos de fadas e fábulas infantis como "Branca de Neve e os sete anões", "Chapeuzinho Vermelho", "Os três porquinhos", "O leão e o rato", "A cigarra e a formiga", "Pinocchio", entre 
outras, as quais poderiam ser sugeridas pelos próprios alunos. Já no percurso idealizado por P12, parte-se do livro infantil "Ceci, um sonho de barata", escrito em português e, posteriormente, traduzido para o italiano pela docente autora do projeto. Está previsto que os encontros tenham como foco uma introdução à língua italiana por meio das discussões decorrentes dos temas abordados nos livros, como sonhos, preconceitos, sentimentos e possíveis diferenças culturais Brasil-Itália relacionadas a esses fatores.

No que se refere às disciplinas de artes, duas docentes propuseram projetos com enfoque em artistas italianos. No primeiro deles, P13 (artes) parte do pressuposto de que a arte é uma linguagem universal e de que atividades didáticas baseadas nas obras dos artistas Lara Favaretto, Ludovica Carbotta e Giancarlo Neri podem abrir espaço para uma educação integral, que tenha como propósito essencial promover o desenvolvimento dos estudantes, considerando as suas dimensões intelectual, social, emocional, física e cultural. A proposta procura difundir a cultura e a língua italiana por meio da obra desses artistas, favorecendo o aprendizado conectado a temas da atualidade, bem como o desenvolvimento da sensibilidade em relação à expressão artística.

O segundo projeto, criado por P14 (artes), tem como foco o artista Leonardo da Vinci e seus projetos de invenções. Pretende-se ensinar que desenhar pode ser uma maneira de pensar, inventar, ampliar o repertório cultural e desenvolver a criatividade.

As sequências didáticas de P15 (geografia), por sua vez, alia artes, matemática e geografia ao ensino de línguas, propondo o estudo da origem, a confecção e a tradução para o italiano de jogos mundialmente conhecidos, como Uno, War, jogo da memória, entre outros.

\subsection{Interculturalidade e ciências}

Além dos projetos da grande área de humanidades, houve dois projetos relativos à disciplina de ciências.

O primeiro deles, concebido por P16, pretende levar ao conhecimento dos alunos a vida e a obra de cientistas italianos nascidos em diferentes momentos históricos. De modo particular, o trabalho em classe girará em torno de figuras como Leonardo da Vinci, Galileu Galilei, Alessandro Volta, Amedeo Avogadro, além de Camillo Golgi, Enrico Fermi e Salvador Luria, explorando a importância desses estudiosos italianos para o aprimoramento da ciência em nível global.

O segundo, projetado por P17, visa ao estudo de doenças que ficaram mundialmente conhecidas em italiano, língua falada pelos cientistas que as descobriram, e ao exame do contexto dessas descobertas, de seus principais sintomas, das partes do corpo humano que acometem, entre outros. A partir desses tópicos, pretende-se levar os alunos a entrar em contato com a cultura da pesquisa científica em outros países, a reconhecer como as investigações conduzidas em outras partes do mundo beneficiam a todos e a perceber a importância crucial da ciência na vida cotidiana. 


\section{Discussão dos projetos e sua relação com a competência intercultural}

No eixo temático "Interculturalidade, imigração, história e geografia", todos os trabalhos têm em comum o anseio de aproximar o Brasil da Itália, visando ao desenvolvimento do conhecimento da cultura italiana a partir de sua influência no Brasil, relacionando os dois países. Em todos os casos, embora sejam propostos conteúdos diferentes, há um objetivo linguístico, que consiste em promover um primeiro contato com a língua italiana, e um objetivo que podemos definir como sociocultural, que se concretiza, por exemplo, no desenvolvimento de uma visão crítica sobre a imigração italiana no Brasil e, de maneira mais específica, na cidade de São Paulo.

Nos projetos elaborados por P2, P3 e P4, para tratar do tema geral escolhido, os professores propõem uma contextualização histórico-social desse período na Itália, a fim de refletir sobre os principais motivos que levaram à migração de tantos italianos ao nosso país. Da mesma forma, é proposto o estudo do contexto histórico e social na cidade de São Paulo nessa mesma época. Os projetos envolvem a reflexão sobre elementos da cultura paulistana que sofreram influência da cultura italiana a partir da forte interação entre os migrantes e os habitantes da cidade. Para tanto, partem da origem dos sobrenomes dos alunos, do estudo de receitas tradicionais, como a pizza napolitana, de expressões e ditos populares de origem italiana difundidos em nossa língua, entre outros.

Como se vê, os conteúdos previstos nesse eixo temático são abordados através de uma visão cross-cultural, que coloca a cultura brasileira ao lado da italiana com o intuito de fomentar comparações entre elas. Essas reflexões, a nosso ver, são fundamentais para promoverem a expansão do que Goodenough chama de "kit de possibilidades", ou seja, um alargamento da compreensão dos alunos sobre os diferentes modos de se viver em diferentes comunidades. Nesse sentido, esses conteúdos são relevantes não apenas por visarem ao aumento da competência comunicativa, mas também por favorecerem a ampliação da competência intercultural do aprendiz, na medida em que fazem com que eles conheçam melhor a cultura da comunidade-alvo e a própria (CORBETT, 2003), além de permitirem uma relativização de si próprio (BYRAM, 1997).

Nos dois trabalhos cujo cerne é a apresentação de como a geografia da Itália impacta a sociedade, observamos um interesse por um enfoque mais local. Embora circunscritas no contexto italiano, acreditamos que propostas originais como a que relaciona relevo e formação sociocultural possam despertar a curiosidade dos aprendizes por conhecer melhor o relevo do local onde vivem, o que os levaria a buscar entender como esse relevo influencia seu dia a dia, desencadeando, em última instância, um maior conhecimento de si mesmo e da própria realidade, como recomendado por Byram (1997).

Entre os trabalhos que compõem o segundo eixo temático, "Interculturalidade e artes", três projetos envolvem o ensino de italiano por meio da música. Além de expressão artística, 
a música é indiscutivelmente um elemento cultural, que, em maior ou menor proporção, pode contribuir para uma caracterização histórica e social de uma determinada cultura.

Esses três projetos colocam em comparação canções italianas e suas versões em português brasileiro, o que permite a realização de diversas atividades que contribuem para o desenvolvimento da competência intercultural. Em primeiro lugar, com um estudo comparativo das letras das canções, é possível refletir sobre semelhanças e diferenças lexicais entre as duas línguas, bem como favorecer atividades de interpretação de texto. Além disso, é possível discutir as características das canções em comparação, como o contexto histórico e social do ano de lançamento, quem é o intérprete em cada país, a recepção do público e as possíveis associações históricas construídas com base nelas ao longo dos anos, viabilizando a compreensão consciente (CORBETT, 2003) das similitudes e diferenças entre os dois países.

Há ainda projetos vinculados às áreas de literatura, artes plásticas e dança, que, além de serem interdisciplinares, ampliam a visão de mundo dos estudantes ao incorporarem práticas que, muitas vezes, não fazem parte da matriz cultural herdada, por exemplo, do ambiente familiar. Nesse sentido, o contato com obras literárias que compõem o cânone mundial, como as fábulas e os contos de fadas, ou com obras traduzidas para o italiano, pode despertar o prazer pela leitura já nos primeiros anos escolares. Da mesma maneira, a realização de dramatizações e apresentações de dança podem tornar os alunos mais conscientes do próprio corpo e das próprias emoções, levando ao maior conhecimento de si (BYRAM, 1997), além de contribuir para o aumento da sensibilidade a expressões artísticas produzidas por artistas de outras nacionalidades, fazendo-lhe perceber a existência de diferentes formas de pensar (SERRA BORNETO, 1998).

No caso específico dos projetos pensados com ênfase nas artes plásticas e no estudo da obra de Leonardo da Vinci, temos propostas que visam ao aprofundamento do conhecimento sobre personalidades que contribuíram e contribuem para o reconhecimento internacional da Itália como um país de grande destaque no campo artístico. Também é possível reconhecer o intuito de propiciar ocasiões em que os alunos façam pesquisas autônomas sobre esses temas, o que vai ao encontro da proposta de Byram (1997), segundo a qual a interculturalidade está atrelada à capacidade de buscar, interpretar e relacionar informações por conta própria sobre sua cultura e/ou a cultura do outro.

Finalmente, no que diz respeito ao terceiro eixo, "Interculturalidade e ciências", mais uma vez estamos diante de propostas interdisciplinares que aliam, cada uma à sua maneira, o ensino de italiano ao de física, química, biologia, matemática e história. São projetos que procuram despertar não apenas o contato com a Itália e com a língua italiana, mas também um saber sobre ciência, tecnologia e sociedade, os quais possibilitam ao estudante compreender e participar ativamente de debates públicos acerca desses temas, realizando o que vem sendo denominado alfabetização científica (LACERDA, 1997; LEAL; SOUSA, 1999; CHASSOT, 2003), de grande importância por permitir que o aluno desenvolva a percepção de como a ciência faz parte de seu dia a dia, aproximando os conteúdos estudados à própria realidade. 


\section{Considerações finais}

O presente relato de experiência procurou apresentar como a interculturalidade foi incorporada por docentes da rede municipal de São Paulo em seus projetos de ensino de italiano, voltados para alunos do ensino fundamental 1 e 2 .

De modo especial, buscamos mostrar que esses docentes, após terem entrado em contato com aulas sobre didática no ensino de línguas e, mais especificamente, sobre a abordagem intercultural, atribuem um papel de destaque a esse componente em suas propostas de ensino.

$\mathrm{Na}$ maioria dos casos, os professores procuram aliar o primeiro contato com a língua italiana às diferentes disciplinas que ministram, tornando os projetos necessariamente interdisciplinares. Além disso, as soluções encontradas pelos docentes levam em consideração a experiência prévia dos aprendizes e o contexto em que se situam, uma vez que muitas das propostas se justificam pela presença italiana na cidade de São Paulo e pela relevância que esse elemento imigrante desempenhou na construção da identidade cultural do local em que moram os estudantes.

Os projetos procuram ainda fomentar o interesse dos alunos pela pesquisa de informações sobre a própria cultura e a cultura do outro para a realização de reflexões, comparações e discussões, estimulando o desenvolvimento da competência intercultural graças a uma perspectiva cross-cultural.

O trabalho aqui descrito deixa claro o anseio pela ampliação dos temas e conteúdos a serem desenvolvidos em sala de aula, mostrando que o percurso realizado pelos docentes ao longo dos encontros do suporte didático os levou a compreender a necessidade de se ir "além da gramática" quando se quer ensinar uma língua. Em última análise, as propostas apresentadas são marcadas de modo particular pelo desejo de ampliar os temas a serem levados à sala de aula.

A partir do efetivo desenvolvimento dos projetos, será possível avaliar e discutir os resultados, que certamente poderão fornecer elementos para direcionar a inserção do componente cultural no ensino da língua italiana.

\section{Referências}

AGAR, M. Language shock: understanding the culture of conversation. New York: Perennial, 2002.

AGAR, M. Emic/etic. In: Ritzer, G. (ed.) The Blackwell Encyclopedia of Sociology. Oxford: Blackwell Publishing, 2007.

AGAR, M. Making sense of one other for another: ethnography as translation. Language e communication. n. 31, p. 38-47, 2010.

BAUMAN, Z. Culture as praxis. Londres: Sage Publications, 1999.

BYRAM, M. Teaching and Assessing Intercultural Communicative Competence. Clevedon: Multilingual Matters, 1997.

CHASSOT, A. Alfabetização científica: uma possibilidade para a inclusão social. Revista Brasileira de Educação, n. 22, p. 89-100, 2003. DOI: https://doi.org/10.1590/S1413-24782003000100009

CORBETT, J. An intercultural approach to English language teaching. Clevedon: Multilingual Matters, 2003. 
GOODENOUGH, W.H. Description and comparison in cultural anthropology. Chicago: Aldine, 1970.

KRAMSCH, C. Language and culture. Oxford: Oxford University Press, 1998.

KUMARAVADIVELU, B. Cultural Globalization and Language Education. Yale University Press, 2008.

LACERDA, G. S. Alfabetização científica e formação profissional. Educação \& Sociedade, n. 60, p. 91-108, 1997. DOI: https://doi.org/10.1590/S0101-73301997000300006

LEAL, M. C.; SOUZA, G. G. Mito, ciência e tecnologia no ensino de ciências: o tempo da escola e do museu. In: Atlas do I Encontro Nacional de Pesquisa em Ensino

de Ciências, Águas de Lindóia-SP, 27-29 nov. 1999.

PIKE, K.L. Language in relation to a unified theory of human behavior. Monton: the Hague, 1967.

SERRA BORNETO, C. S. C'era una volta il metodo. Tendenze attuali nella didattica delle lingue straniere. Roma: Carocci, 1998

SPENCER-OATEY, H. What is culture? A compilation of quotations. GlobalPAD Core Concepts, 2012.

VYGOTSKY, L.S. The history of the development of higher mental functions. The Collected Works. New York: Plenum Press, vol. 4, 1997.

Recebido em: 21/06/2021 (versão atualizada: 06/08/2021)

Aprovado em: 27/08/2021 